\title{
Investigation of tropical coastal forest regeneration after farming and livestock grazing exclusion
}

\author{
Elly Josephat Ligate ${ }^{1}$ Chengzhen $\mathrm{Wu}^{2,3} \cdot$ Can Chen $^{3}$
}

Received: 12 July 2017 / Accepted: 6 February 2018/Published online: 10 September 2018

(C) The Author(s) 2018

\begin{abstract}
It is critical to understand how forests regenerate after the exclusion of human induced disturbances because the regenerating species drive the renewal of resources and ecosystems, which in turn support human beings locally and globally. This study of forest regeneration was conducted in the tropical coastal forest ecosystems of Tanzania at Uzigua Forest Reserve (24,730 ha) in the Pwani Region. We collected data from adult trees in 47 sampling plots $(25 \times 25 \mathrm{~m})$ randomly established in closed forest sites (control) and in sites disturbed by farming and livestock grazing. Sapling and seedling data were collected and analyzed in $2 \times 2 \mathrm{~m}$ nested subplots. Plots in the closed forest had higher mean basal area and volume for adult trees than those in sites disturbed by farming and livestock grazing. Plots in sites disturbed by farming had the highest Shannon-Wiener index for seedlings and saplings, followed by closed forest and livestock grazed sites. Closed
\end{abstract}

Project funding: This study is supported by National Key Research and Development Project (2017YFD060130403), Fujian Forestry Science and Technology Research Project (2018FSR04008),

International Science and Technology Cooperation Program of Fujian Agriculture and Forestry University (KXB16008A).

The online version is available at http://www.springerlink.com

Corresponding editor: Zhu Hong.

Chengzhen $\mathrm{Wu}$

fjwcz@126.com

1 College of Life Sciences, Fujian Agriculture and Forestry University, Fuzhou 350002, People's Republic of China

2 Wuyi University, Fuzhou 350002, People's Republic of China

3 College of Forestry, Fujian Agriculture and Forestry University, Fuzhou 350002, People's Republic of China plots and farmed plots had higher Simpson's index for seedlings and saplings than in grazed sites. Plots in farmed and livestock-grazed sites had a higher Simpson index for adult trees than in closed sites. Equitability of seedlings and saplings was highest in closed forest sites, followed by farmed and livestock grazed sites. Plots disturbed by farming had higher equitability for adult trees than in livestock-grazed and closed sites. Moreover, plots disturbed by farming and grazing had a higher importance value index for seedlings than in closed sites. Plots in closed forests had higher sapling importance values than in farmed and grazed sites. Again, plots in closed forest had a higher importance value for adult trees than in farmed and grazed sites. The differences in tree species subcategories of regeneration across land-use indicates that farming and livestock grazing disturbances create heterogeneous microhabitats, which positively or negatively affects regeneration capacity of species after exclusion.

Keywords Coastal forests · Disturbance - Diversity · Regeneration

\section{Introduction}

Protecting remnants of coastal forests and recovering disturbed sites are important worldwide concerns (Potter 2014; Mligo 2015; World Bank 2016). Common strategies used locally and globally include excluding human settlements, crop-agriculture (cropped), and livestock grazing (Navroodi 2015; Tadesse and Kotler 2013; Schieltz and Daniel 2016). These efforts aim to allow the regeneration of trees and other vegetation since tropical forests have a pronounced ability for self-maintenance through regeneration (Sundarapandian and Swamy 2013). However, under 
the current exclusion management options, there is insufficient documentation about the distribution and concentration of trees diversity in response to disturbances, particularly in the tropical coastal forests.

Deforestation due to human pressures and poor forest management systems affects forest ecosystems (Guerrero and Bustamante 2007; Halter 2016; Bonari et al. 2017). Forest disturbances and degradation affect the compositional structure and functions of forest ecosystems at large (Bargali et al. 2013) and contribute to forest biodiversity decline or loss (DeFries et al. 2010), primarily through agriculture, pole cutting, charcoal burning, timber harvesting, and settlements, especially in the tropics (Majumdar and Datta 2014; Keenan et al. 2015; Bonari et al. 2017). Disturbances reduce the capacity of forest to regenerate, function, and offer various ecological services (Joyi et al. 2015; Thompson et al. 2009; Kimaro and Lulandala 2013). However, some degree of disturbances can be beneficial by increasing biodiversity and nutrient circulation. These disturbances are thus considered important for long-term sustainability and productivity of most ecosystems (Kalaba et al. 2013). Indeed, disturbances are important in modifying forest structures (i.e., stand parameters and species diversity), thus helping forests to undergo successional stages and maintain value. Unfortunately, in many cases, these structures are affected by natural and anthropogenic activities under varied environmental conditions (Bargali et al. 2013).

We conducted this study in the forests along the coastal zone of Tanzania, an ecological area rich in biodiversity with about 190 tree species, of which 92 are endemic (Mligo 2015). However, as in many other tropical forests, crop farming, livestock grazing, timber harvesting, and charcoal-making are causing the forests to disappear at an alarming pace (Devi and Yadava 2006). As a result, tropical coastal forests in the coastal zone of Tanzania have lost about $69 \%$ of their primary vegetation (Silayo et al. 2006; Mligo 2015). If not abated, degradation will further threaten about 1500/300,000 (i.e., 0.5\%) of global vascular plant species in this zone (Mligo et al. 2009). Cropping and livestock grazing are the main human activities accelerating the degradation of coastal forests in Tanzania (Kimaro and Lulandala 2013), encroaching on the forests, which cover about $850 \mathrm{~km}^{2}$ along the coastal zone (Kimaro and Lulandala 2013) and altering the distribution and structure of the forests (Ares et al. 2007; Amato et al. 2011). Such changes in spatial and temporal patterns and the subsequent regeneration capacity are jeopardizing forest management efforts (Huang et al. 2003; Merganic et al. 2012); yet the responses of coastal forests, such as those comprising our study area, to cropping and grazing disturbances have not been studied.
This first study compares the regeneration of trees across land-uses after crop-agriculture and livestock grazing exclusion in tropical coastal forests of Tanzania and presents tree composition, structure and regeneration potential across land-use sites (Bharathi and Prasad 2015). We used data from the Uzigua Forest Reserve along the coastal zone of Tanzania to serve as an important stage and contributing measure for designing sustainable strategies for coastal forest management (Guerrero and Bustamante 2007; Sundarapandian and Swamy 2013) and understand tree responses after disturbances and the exclusion of human activities; knowledge of forest structure, including tree regeneration, is a critical determinant of forest direction to attain sustainable management (Bargali et al. 2013). We tested the following two hypotheses: (1) Regenerating trees are more abundant in closed forests than in cropped and livestock-grazed sites. (2) The species of regenerating trees are more diverse in closed forest sites than in cropped and livestock-disturbed sites. The work was guided by two questions: (1) How do variables for seedlings, saplings and adult trees (density, diameter, basal area and volume) in closed forests differ from those in cropped and livestock grazed sites? (2) How do species diversity indices for the regenerating trees differ between and across closed forests, cropped and grazed sites?

\section{Materials and methods}

\section{Description of the study area}

Data were collected in the Uzigua Forest Reserve (UFR) (Fig. 1) in the Bagamoyo District of the Pwani Region in the coastal zone of Tanzania. This forest reserve covers about 24,730 ha within $100 \mathrm{~km}$ from the Indian Ocean (Godoy et al. 2011; URT 2015). The UFR is managed by the central government under the Forest and Bee Keeping Division of the United Republic of Tanzania, Ministry of Natural Resources and Tourism (URT 2015). The climate is humid with $690-1000 \mathrm{~mm}$ annual rainfall. The temperature is oceanic with a mean annual temperature of $24.3{ }^{\circ} \mathrm{C}$. The soils are well-drained, red sand clay, loamy with brown friable top-soils covered by decomposing litter. The area is undulating with continuous hills ranging from 300 to $600 \mathrm{~m}$ above sea level (Silayo et al. 2006). Vegetation is very diverse, making it among the richest plant community stands in eastern Tanzania (Silayo et al. 2006). Unfortunately, due to poor protection and surrounding settlements, the entire forest is affected by anthropogenic activities such as fuel-wood collection, grazing pressure, and agricultural encroachments. These activities threaten plant species, which are among those found in the 34 world biodiversity hotspots (Mligo 2015). Gum arabic trees 


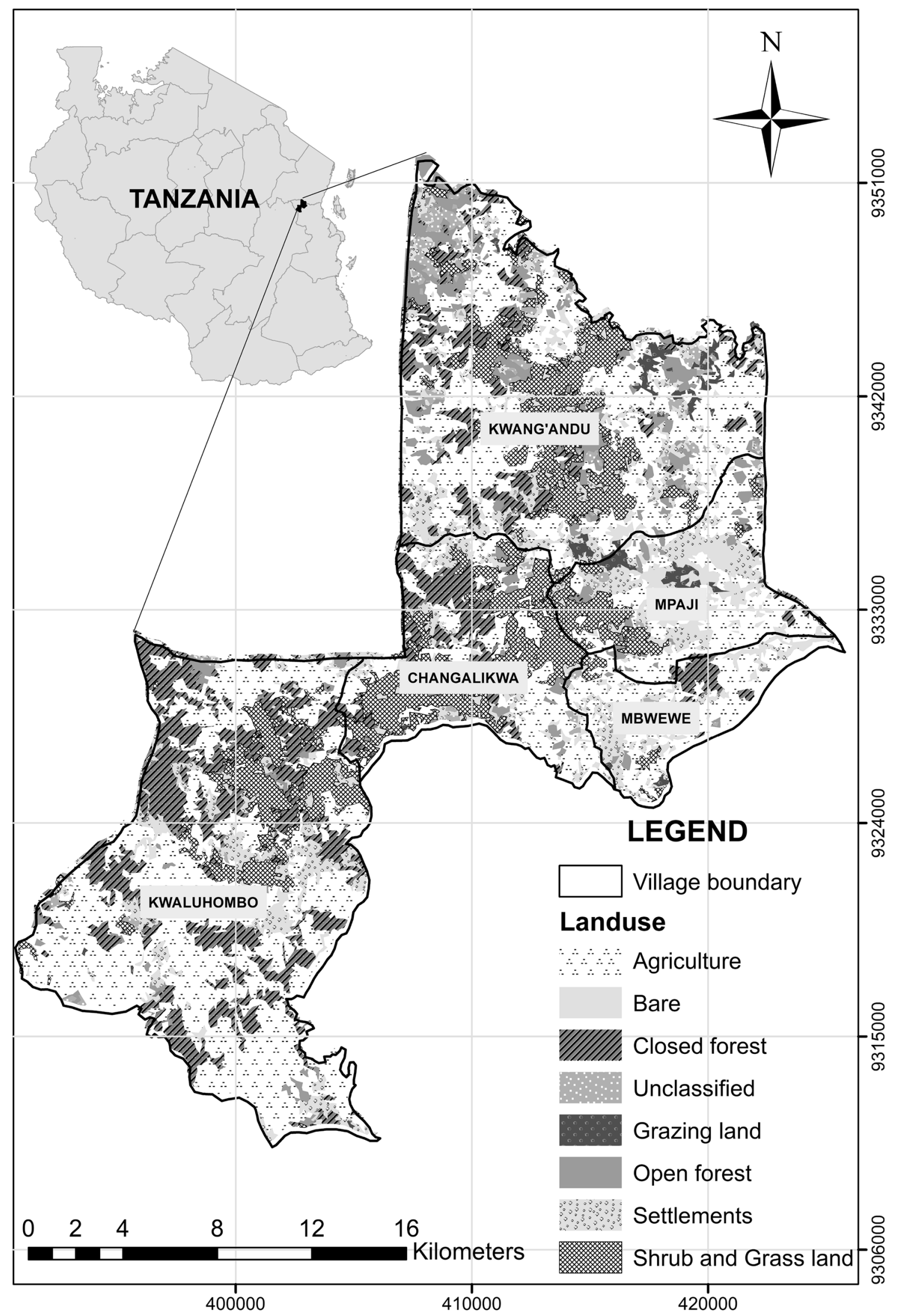

Fig. 1 Study area and characteristics of Uzigua Forest Reserve in Bagamoyo District, Tanzania 
(Acacia sp.), thicket combretum (Combretum sp.), red woods (Brachystegia sp.) and tamarind (Tamarindus sp.) are among the dominant trees in this forest (Silayo et al. 2006). Because of more than 50 years of disturbance, this forest was purposely chosen to serve the objectives of this study because it provides microsites for comparing regeneration responses.

\section{Data collection}

Data were collected from May to August 2016 using the stratification field inventory approach (Jayakumar et al. 2011; Tomppo et al. 2014; URT 2015). Land-use (LU) classes were identified and developed by checking images and corresponding mean layer values and the normalized difference vegetation index (NDVI). The NDVI was used with the support vector machine (i.e., a machine used for classification and regression analysis) for image processing and production of LU classes (Ustuner et al. 2015). Closed forest, open forest, shrub and grassland, agriculture, grazing land, settlements and bare lands were classified. From these classes, closed forest (CFS), agriculture (ADS), and grazing lands (LGS) were purposely selected. Local people supported the identification of LU sites based on the history of crop and livestock production activities in the study area. The selected LU sites were surveyed to gauge the response of trees 3 years after the exclusion of human activities. We chose to compare regeneration across CFS, ADS and LGS because farming and livestock grazing are the major factors disturbing tropical forests (Kimaro and Lulandala 2013; Keenan et al. 2015).

\section{Sampling procedures}

Ground forest inventories were carried out by measuring and identifying tree species subcategories (i.e. seedlings, saplings and adults) in the CFS, ADS and LGS (Axelsson et al. 2012). Because human activities are not uniformly distributed, the random selection of sites and the establishment of sampling plots were carried out after the stratification of the LU sites. Tree subcategories stand and composition variables were recorded from each plot in each LU site. Forty-seven (47) quadrats of $25 \times 25 \mathrm{~m}$ were laid out to collect data for adult trees, while nested plots of $2 \times 2 \mathrm{~m}$ (within the established $25 \times 25 \mathrm{~m}$ plots) were laid out for seedlings and saplings (Shankar 2001; Bharathi and Prasad 2015). Stems with a diameter $\geq 20 \mathrm{~cm}$ at breast height (dbh) (approximately $1.34 \mathrm{~m}$ height above the ground) were counted as trees. All tree species with a diameter $<20 \mathrm{~cm}$ was considered as regenerates in the following subdivisions: (1) seedlings were $<0.40 \mathrm{~m}$ tall; (2) saplings were $\geq 0.40 \mathrm{~m}$ to $<1 \mathrm{~m}$ heights as adapted from Bharathi and Prasad (2015). Trees were identified in the field using field guide books of Lovett et al. (2006) and Dharani (2011). Local people in the study area and qualified botanists assisted with tree species identification and data collection. In addition, some voucher samples were taken to Sokoine University of Agriculture for further identification. In this work, 70 species belonging to 25 families were studied.

\section{Data analysis}

From the tree species checklist, the following stand parameters were initially calculated: (1) number of live trees per unit area (N/ha), (2) basal area (BA) of live trees $\left(\mathrm{m}^{2} / \mathrm{ha}\right)$, and (3) volume of live trees $\left(\mathrm{m}^{3} / \mathrm{ha}\right.$, estimated as $v=g h f, g=$ basal area of the tree, seedling or sapling $\left(\mathrm{m}^{2} /\right.$ ha), $h=$ height of the tree $(\mathrm{m})$ and $f=$ form factor of 0.5 , an average of natural forest factors between 0.4 and 0.6 (Philip 1983; Hitimana et al. 2004). Basal area was calculated as $\mathrm{BA}=\left(\mathrm{dbh}^{2} \times \pi\right) / 4, \mathrm{dbh}=$ diameter at breast and $\pi=3$.14.Calculations of paired mean and $t$-values, used for variability comparisons and decision making between and across land-uses, were done in Excel (Microsoft, Redmond, WA USA) and Statistical Package for Social Sciences (version 18, SPSS, Chicago, IL, USA) for computation (Joyi et al. 2015). The results were considered significant at $5 \%$ level of significance.

Species diversity indices were used to compare the biodiversity of seedlings, saplings and adult trees across land uses (Axelsson et al. 2012; Merganic et al. 2012). Shannon-Wiener, Shannon equitability, Simpson diversity and IVI were computed for each tree subcategory in each LU site. (1) The Shannon-Wiener diversity index was computed as $H^{\prime}=\Sigma P_{i} \times \ln P_{i}, H^{\prime}=$ index of diversity; $P_{i}=$ decimal fraction of a relative basal area (Shannon and Wiener 1963). The interpretation of results from this index was that the Shannon-Wiener index increases with the number of species in the community. (2) The Shannon equitability (evenness) index was calculated as $H^{\prime} E=H^{\prime} / H_{\max }, H_{\max }=\ln S$ (species richness). The value of $H^{\prime} E$ ranges from zero (0) to one (1), in which one indicates complete evenness. The equitability interpretation decision criterion was that, the less variation in communities between the species, the higher $H^{\prime} E$ was. (3) The Simpson's index was computed as $D=\sum\left(n_{i} / N\right)^{2}$, $D=$ index of dominance, $n_{i}=$ number of individuals of species $i$ in the sample, $N=$ the total number of individuals (all species) in the sample (Simpson 1949). Determination of values for the comparison between and across LU sites was done based on the criterion that the greater the value of Simpson's index, the lower the species diversity in the community and vice versa. (4) The IVI of each tree species was determined from the sum of the relative frequency, 
density, and BA as adopted from (Supriya and Yadava 2006; Hunter et al. 2013). All these values were compared between and across LU sites.

\section{Results}

\section{Species density}

A total of 70 species belonging to 25 families were sampled from CFS, ADS and LGS. These families were grouped into five major categories based on their percentage contribution to the main sample: (1) Fabaceae (26\%); (2) Combretaceae (7\%); (3) Malvaceae and Meliaceae (4\%), (4) Anacardiaceae, Annonaceae, Apocynaceae, Bignoniaceae, Capparidaceae, Moraceae, Phyllanthaceae, and Sapotaceae (3\%); and (5) Asteraceae, Araliaceae, Balanitaceae, Bombacaaceae, Clusiaceae, Dichapetalaceae, Ebenaceae, Euphorbiaceae, Loganiaceae, Rubiaceae, Rutaceae, Santalaceae, and Verbenaceae (1\% of each family). Results show that the average population density (N/ha) of seedlings was 10 for CFS, 45 for LGS, and 85 for ADS. Sapling density ranged from 15 for CFS, 20 for ADS, and 65 for LGS. Adult tree density was 130 for CFS, 65 for ADS, and 30 for LGS (Fig. 2). Species of seedlings and saplings with sizeable frequency were Combretum molle, Cynometra webberi, Dialium holtizii, Ficus sur, Hymenea verrucosa, Khaya anthotheca, Millicia excelsa, Millettia stuhlmannii, Sclerocarya birrea, and Stercularia appendiculata. A large component of the adult tree density consisted of Acacia brevispica, C. webberi, C. molle, $H$. verrucosa, D. holtizii, M. stuhlmannii, Terminalia sambesiaca, and Vitex zanzibarensis. In ADS and LGS, the

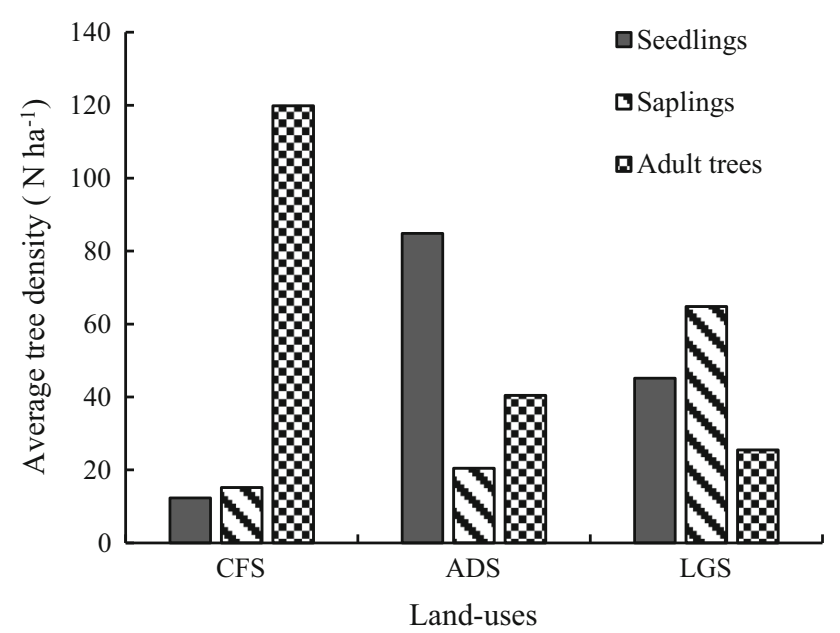

Fig. 2 Number of tree subcategories per hectare $\left(\mathrm{N} \mathrm{ha}^{-1}\right)$ for each land-use (where CFS is closed forest sites, ADS is agriculture (crop farming) disturbed sites and LGS is sites disturbed by livestock grazing) density of adult trees was largely composed of a few remnant trees such as Acacia brevispica, A. polyacantha, A. senegalensis, Afzelia quanzensis, Cassia abbreviata, Combretum collinum, Cussonia spicata, Erythrina abyssinica, Sterculia abbreviata, and Strychnos henningsii.

\section{Diameters of tree across land uses}

Tree subcategories diameters (seedlings, saplings and adults) differed across LU sites (Fig. 3). In CFS, seedling diameters ranged from 4 to $10 \mathrm{~cm}, 8$ to $12 \mathrm{~cm}$ for saplings, and 13 to $78 \mathrm{~cm}$ for adult trees. In ADS and LGS, seedlings and saplings had similar average diameters and trends that ranged from 3 to $6 \mathrm{~cm}$ and 7 to $12 \mathrm{~cm}$ respectively, while trees had a dbh between 25 and $31 \mathrm{~cm}$. Tree species, that had large dbh included Acacia polyacantha, Abutilon mauritianum, Albizia versicolor, Combretum molle, Cynometra webberi, Dialium holtizii, Ficus sur, Hymenea verrucosa, Khaya anthotheca, Millicia excelsa, Pteleopsis myrtifolia, Sclerocarya birrea, Tamarindu sindica, and Terminalia sambesiaca. The following trees had small a dbh across all the LU sites: Ficus sur, Cussonia spicata, Uvaria acuminata, Trichilia emetica, and Millettia stuhlmannii. Small dbh predominated for seedlings and saplings in tree populations across the LU sites.

\section{Basal area of trees across land uses}

Basal area $\left(\mathrm{BA}, \mathrm{m}^{2} / \mathrm{ha}\right)$ differed across LU sites for all tree subcategories. Seedlings had a BA of 0.20 to $1.30,0.30$ to 0.69 and 0.2 to 0.28 in CFS, ADS and LGS, respectively; sapling BAs ranged from 0.2 to $1.47 ; 0.5$ to 1.13 and 0.20

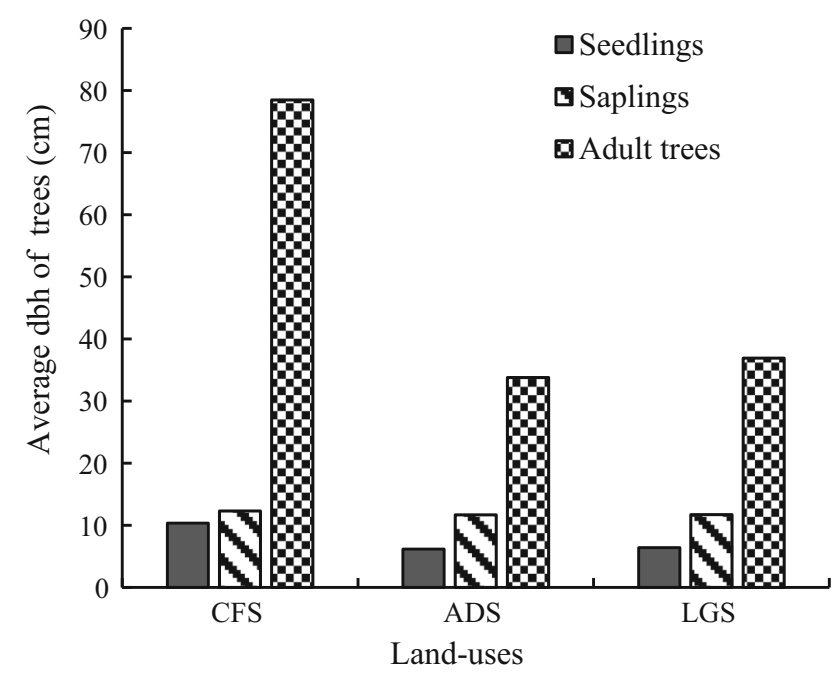

Fig. 3 Average dbh of trees in the three subcategories for each landuse (where CFS is closed forest sites, ADS = agriculture (crop farming) disturbed sites and LGS $=$ sites disturbed by livestock grazing) 
to 0.64 in ADS, CFS and LGS; adult tree BA ranged from 1.82 to $73.50,1.13$ to 24.62 and 0.50 to 7.96 for CFS, LGS and ADS, respectively. There was significant mean paired differences in BA between and across LU sites (Table 1). At $p \leq 0.05, t$-values for seedlings paired mean (in brackets) were 0.83 (CFS and ADS), 13.08 (CFS and LGS), 11.68 (ADS and LGS); for saplings, they were 0.83 (CFS and ADS), 13.08 (CFS and LGS), 11.68 (ADS and LGS), and for adult trees, they were 10.24 (CFS and ADS), 9.33 (CFS and LGS) and 3.36 (ADS and LGS).

\section{Volume of trees subcategories across land-uses}

A small volume $\left(\mathrm{m}^{3} / \mathrm{ha}\right)$ for seedlings and saplings was recorded, unlike in adult trees across all LU sites. Seedling volume ranged from 0.1 to $0.17,0.2$ to 0.8 and 0.10 to 0.80 for CFS, ADS and LGS, respectively, in CFS. Sapling volume was 0.27 to $1.03,0.20$ to 1.02 and 0.13 to 0.25 in CFS and LGS and ADS, respectively; adult tree volume ranged from 0.60 to 414 in CFS, 0.61 to 135 in LGS and from 0.60 to 43.78 in ADS. Mean paired differences varied significantly in volume between and across LU sites (Table 1). At $p \leq 0.05, t$-values for seedling paired means (in brackets) were 5.46 (CFS and ADS), 7.51 (CFS and LGS), 3.68 (ADS and LGS); for saplings, values were 0.83 (CFS and ADS), 13.08 (CFS and LGS), 11.50 (ADS and LGS); for adult trees, they were 10.24 (CFS and ADS), 9.33 (CFS and LGS) and 3.36 (ADS and LGS). The order of seedlings volume was CFS $>$ ADS $\gg$ LGS. The order was similar for saplings, while in adult trees the order was CFS $>$ LGS $>$ ADS.

\section{Shannon-Wiener index}

Seedlings and saplings Shannon-Wiener indices in order were ADS $>$ CFS $>$ LGS and ADS $>$ CFS $>$ LGS. There was a significant variation between ADS saplings but not between CFS and LGS. The Shannon-Wiener index for adult trees was CFS $>$ LGS $>$ ADS (Table 1). At $p$ $\leq 0.05, t$-values for seedlings for each paired mean (in brackets) were 1.35 (CFS and ADS), 3.23 (CFS and LGS), 6.14 (ADS and LGS); for saplings, the values were 0.98 (CFS and ADS), 625.97 (CFS and LGS), 7.44 (ADS and LGS), and for adult trees, they were 1.18 (CFS and ADS), 1.18 (CFS and LGS) and 5.33 (ADS and LGS).

\section{Simpson's index across land-uses}

Simpson's index in CFS and ADS for seedlings and for saplings had similar diversity values but were higher than those in LGS. These results indicate that diversity was higher diversity for seedlings and for saplings in LGS than in CFS and ADS. But adult tree diversity was lower in CFS 
than in any other LU site. Variations in paired mean differences between and across LU sites are shown in Table 1 . At $p \leq 0.05$, the $t$-values for seedlings for each paired mean (in brackets) were 20.37 (CFS and ADS), 74.05 (CFS and LGS), 60.36 (ADS and LGS); for saplings, the values were 38.31 (CFS and ADS), 242.92 (CFS and LGS), 12.39 (ADS and LGS), and for adult trees, they were 18.16 (CFS and ADS), 160.71 (CFS and LGS) and 0.07 (ADS and LGS).

\section{Shannon equitability}

The Shannon equitability shows that seedlings in ADS and LGS had lower values than CFS, while saplings equitability showed a high value in CFS, followed by LGS and then ADS. The mean equitability value was lower in CFS adult trees than in ADS and LGS. These observations showed a lower frequency of seedlings in CFS than in ADS and LGS, and lower sapling frequency in LGS and CFS than in ADS. Therefore, adult trees' frequency was higher in CFS than in ADS and LGS. The paired mean variation across LU sites as shown in (Table 1). At $p \leq 0.05$, the $t$ values for seedlings paired mean (in brackets) were 137.75 (CFS and ADS), 104.91 (CFS and LGS) and 208.27 (ADS and LGS); for saplings, values were 0.00 (CFS and ADS), 0.81 (CFS and LGS) and 0.52 (ADS and LGS), and for adult trees, they were 1.18 (CFS and ADS), 0.72 (CFS and LGS) and 1.13 (ADS and LGS).

\section{Important value index across land-uses}

Seedlings in LGS scored the highest IVI, followed by those in CFS and ADS. The mean value of saplings IVI was highest in CFS followed by ADS and LGS. Adult trees had highest IVI in CFS, followed by ADS and LGS. The trend in the IVI indicated a high dominance of adult trees in CFS, while ADS and LGS had higher regeneration values of seedlings and saplings. Abutilon mauritianum, Acacia senegalensis, Albiziapetersiana, Combretum collinum, Dalbergianitidula, Holarrhena pubescens, Julbernardia globiflora, Millettia stuhlmanii, Ormocarpum kirkii, Sclerocarya birrea, Tamarindus indica, Uvaria acuminata, and Xeroderris stuhlmannii dominated seedlings and saplings components, while A. senegalensis, Brachystegia boehmii, $H$. pubescens, Khaya anthotheca, S. birrea, and T. indica dominated the adult trees IVI component in CFS. Species that had large IVI in seedlings and saplings were A. mauritianum, A. petersiana, Afzelia quanzensis, Brachytergia microphylla, Combretum schumannii, Cynometrawebberi, Erythrina abyssinica, H. pubescens, J. globiflora, O. kirkii, $S$. birrea, T. indica, and X. stuhlmannii, while adult trees were dominated by a few species such as A. petersiana, A. quanzensis, C. schumannii, J. globiflora, Pterocarpus rotundifolius, Sorindeia madagascariensis, and $X$. stuhlmannii. Seedlings and saplings IVI in LGS were largely represented by $A$. mauritianum, Acacia polyacantha, A. quanzensis, B. microphylla, P. rotundifolius, T. indica, while A. quanzensis, B. microphylla, Hymenea verrucosa, and $P$. rotundifolius had a greater IVI than other adult trees. The mean values of tree species dominated the IVI across the three land-uses are shown in Fig. 4.

\section{Discussion}

Like many other forests in the tropics, coastal forests are among the richest ecosystems in plant species (Devi and Yadava 2006). From our findings, there were significant differences in the number and composition of species across LU sites. These results confirmed the hypothesis that there are significant variations in stand variables and diversity indices of regenerating trees between CFS and disturbed sites (ADS and LGS) at 5\% level of significance. The variation in tree stand variables and diversity indices across the plots indicates that tropical forests have a different natural ability to regenerate after disturbances and exclusion of human activities (Sundarapandian and Swamy 2013).

Fewer trees were recorded in the present study than found by Mligo (2015). This difference is possible because many of the previous studies did not consider tree stand variables and diversity values, particularly from ADS and LGS seedlings and saplings. The variation in plant density recorded in this study area shows that forests subjected to different disturbances regenerate differently as supported by Wekesa et al. (2015). ADS had more seedlings and saplings than in CFS, indicating that disturbances have some beneficial effects as found by others (Hessenmöller et al. 2013; Kalaba et al. 2013; Wekesa et al. 2015 and Lu et al. 2017), though at small spatial scales (Duah-gyamfi et al. 2014). Also, habitats modified by farming might also promote regeneration and are measurable after some years of human activities exclusion (Navroodi 2015). However, the beneficial effects of disturbances observed in our study are contrary to other findings (Carnevale and Montagnini 2002; Hooper et al. 2002). The dissimilarities in regeneration responses are partially explained by the fact that different ecosystems respond differently to disturbances. Indeed, the high population density of seedlings and saplings in ADS provides potential stock for future adult trees in these sites (Sundarapandian and Swamy 2013). Nevertheless, not all regenerating trees will reach adult stages because they are subjected to multiple stresses (e.g. pest pressure, light, water and nutrient limitation), which can cause the gradual disappearance of some species (Majumdar and Datta 2014; Comita 2014; Amlin et al. 2014). 
The variations in this study across LU sites show that impacts of stresses in regeneration are neither equal, nor at the same rate (Golluscio et al. 2009; Cierjacks et al. 2008).

Livestock grazing sites had lower seedling and sapling density in comparison to ADS, perhaps because livestock grazing does not provide microsites conducive to regeneration. Poor regeneration in LGS is due to livestock (e.g., cattle) compacting the soil, and consuming and trampling the regenerating trees (Cierjacks et al. 2008; Navroodi 2015). Seeds are also incorporated deeper into the soil, which may hinder germination of some seeds. On the other hand, cultivated sites allow the soil to be loosened, and seed removal is minimized. Low seedling and sapling density in CFS indicates these sites have shifted from pioneer to non-pioneer communities (Duah-gyamfi et al. 2014). The structure of forests in ADS and LGS are still

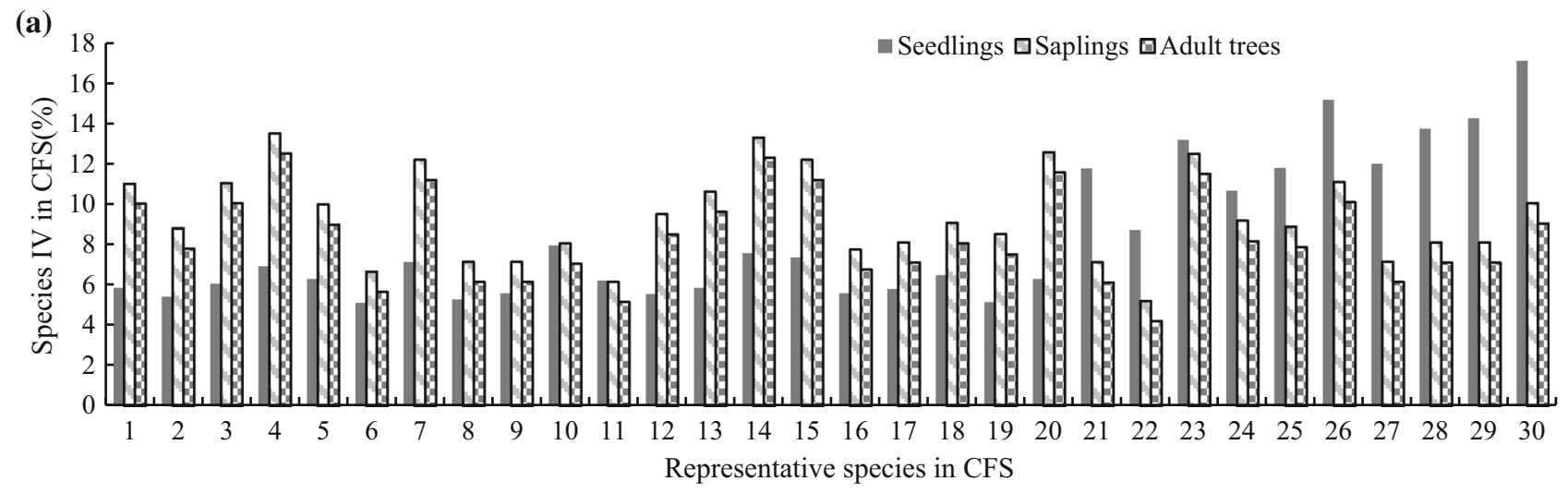

(b)
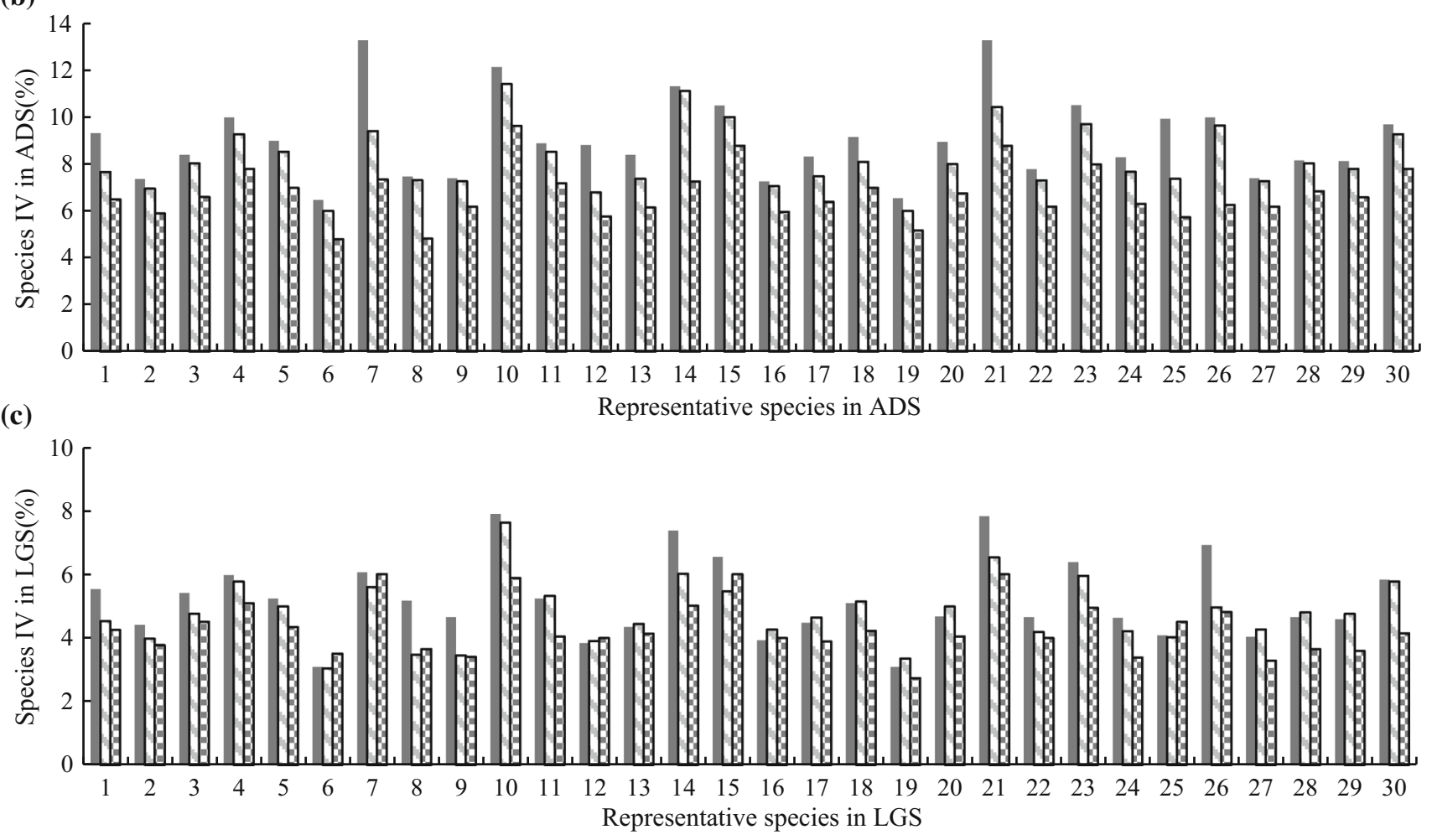

Fig. 4 Importance value indices (IVIs) of trees in across land-uses (where CFS $=$ closed forest sites, ADS $=$ agriculture (crop farming) disturbed sites and LGS = sites disturbed by livestock grazing. The species in figure are numbered as follows: 1. Abutilon mauritianum, 2. Acacia polyacantha, 3. Acacia senegalensis, 4. Afzelia quanzensis, 5. Albiziapetersiana, 6. Brachystagia boehmii, 7. Brachystagia microphyla, 8. Pterocarpus rotundifolius, 9. Combretum collinum, 10. Cynometra webberi, 11. Combretum schumannii, 12. Dalbergia nitidula, 13. Dalbergia obovata, 14. Erythrina abyssinica, 15. Ficus stuhlmannii, 16. Hymenea verrucosa, 17. Holarrhena pubescens, 18. Julbernardia globiflora, 19. Kyaya anthontheca, 20. Millettia stuhlmanii, 21. Mimusops zeyheri, 22. Ormocarpum kirkii, 23. Sclerocarya birrea, 24. Senna singuena, 25. Sterculia abbreviata, 26. Tamarindus indica, 27. Terminalia sambesiaca, 28. Tricalysia ovalifolia, 29. Uvari aacuminata, 30. Xeroderris stuhlmanii 
under the former stage of succession, with the danger of losing many species because of further disturbance stresses (Comita 2014). Farming activities in ADS created microsites, which resulted in the rapid growth of seedlings, allowing more rapid recruitment and faster growth of pioneers than in LGS and CFS (Duah-gyamfi et al. 2014).

High tree population density in ADS and LGS is supported by the work of Eludoyin (2016); seedlings and saplings make up larger proportions than adult trees of many tropical forests. However, some adult trees, primarily Afzelia quanzensis, Brachystergia spiciformis, Cynometra webberi, and Pterocarpus angolensis, in ADS and LGS survived as remnants. Interestingly, these trees passed into protected status by chance, not merely for protection or conservation values, but they were kept to attain certain diameters and heights for timber production. Therefore, exclusion saved their lives, and thus they resumed their protected status and facilitated the parental stock roles (e.g., seed production) helping regeneration in ADS and LGS. It is possible to find that the structure of forest developed from ADS and LGS after exclusion is dissimilar to the previously protected sites because human activities and natural disturbances affect the direction of forest structures (Bargali et al. 2013; Hessenmöller et al. 2013). The variation in forest stand structures and compositional settings for seedlings, saplings and adult trees revealed across LU sites indicates that human activities have either positive or negative impacts on the coastal forest ecosystems.

The mean diameter of seedlings and saplings in ADS and LGS was below that found in CFS. In both LU sites, the average diameter was below that recorded in many tropical forests (Mligo 2015). This variation in mean diameter between different studies can partially be justified by differing sample sizes, species compositions, and the age and degree of disturbances (Sundarapandian and Swamy 2013). Also, the small diameters in ADS may be due to the higher population density of seedlings and saplings than in CFS; competition for available resources is likely greater, hence affecting the size of seedlings and saplings more than adult trees (Sundarapandian and Swamy 2013). The competition seems to be severe, especially when soil organic matter is a limiting factor as in the case of crop-agriculture and livestock grazing disturbed sites (Amlin et al. 2014).

The mean basal areas progressively increased from seedlings to saplings to adult trees with same size diameters across all the sites, as also noted by Shankar (2001). Therefore, BA differed significantly across LU sites. The BA in CFS was significantly greater than in ADS and LGS. The BA across all plots was affected by differences in tree diameters. Tree species with large diameters contributed to the significant large BA especially in the adult tree subcategory. The larger diameters of species within CFS, unlike in ADS and LGS, contributed to a greater mean BA in CFS. The variation in BA in turn affected the volume of trees in all LU sites. The mean volume of trees increased from seedlings to adults in CFS unlike in ADS. Volume variation between CFS and ADS indicates that, although ADS had a large number of young trees, they contributed less to the volume than did the few adult trees in CFS. Basically, the large volume in LGS increased from seedlings to adult trees because this LU site contained the second largest number of adult trees. Across all LU sites, the volume was affected by BA and heights at large. That is why adult trees in CFS had a larger volume than seedlings and saplings. The mean volume of adult trees obtained in this study is within the range reported by Mligo et al. (2009, 2015). The mean volume for comparison with the existing studies was mainly contributed by Acacia brevispica, Combretum mole, Ficus stuhlmanii, Sclerocarya birrea, Sterculia abbreviata, and Terminalia sambesiaca, which were more frequent than other species across all LU sites. There were fewer individuals of species that are the most overharvested for timber and construction poles, e.g., Cynometra webberi, Dalbergia melanoxylone, Dalbergia nitidula, Dialium holtizii, Ficus sur, Hymenea verrucosa, Khaya anthotheca, Millicia excelsa, Millettia stuhlmannii, Pteleopsis myrtifolia, Pterocarpus angolensis, and Pterocarpus rotundifolius.

Species diversity differed across LU sites because species differ in their ability to regenerate and survive in different environmental conditions (Bargali et al. 2013). The ADS and LGS had significantly lower variation in diversity indices, contrary to the results of Hessenmöller et al. (2013), but this low diversity in disturbed sites agrees with the findings of Guerrero and Bustamante (2007) and indicate that post-anthropogenic disturbance regeneration differs from one LU site to another. It also shows that not all species have an equal capacity to regenerate (Jones et al. 2004). These results confirm that human activities have modified UFR habitats, and thus crop-agriculture and livestock grazing have imposed forest structural and diversity changes (Guerrero and Bustamante 2007). Low diversity in ADS and LGS is partly explained by recognizing that some plants have a slower capacity to regenerate; hence it is not possible to quantify their regeneration values 3 years after exclusion. However, our findings set a diversity baseline to describe regeneration potential in disturbed coastal forests (Devi and Yadava 2006; Duahgyamfi et al. 2014). They also provide input for mapping future spatial and temporal coastal forest structures and diversity dynamics after exclusion and set forth the challenge that exclusion increases population density and/or trees diversity (Jones et al. 2004). 
In regards to species richness, ADS and LGS had lower values compared with CFS sites, contrary to a study by Bargali et al. (2013). This contradiction can possibly be explained by the varying degrees of disturbance and kinds of species between different studies affecting the occurrence of certain species in a given location. However, low species richness can be used as a criterion to judge that the Uzigua Forest Reserve should be included among the degraded ecosystems along the coastal zone of Tanzania. This observation falls within the existing documentation that Tanzania coastal forests have lost at least $70 \%$ of their species (Silayo et al. 2006; Mligo 2015). The similarity index was below that in earlier studies (i.e., 5.06 and 5.40) for tropical forests (Devi and Yadava 2006). These differences are probably caused by variations in sampling methods, sample size, and measurements in the field, which in many cases affect results and comparisons (Jayakumar et al. 2011). Indeed, the deviation in similarity index obtained in this study is among the best confirmation that the Uzigua forest has been disturbed and degraded for the past 50 years. Human activity pressure has affected the biodiversity of coastal forests, even though some species have good potential to regenerate and thrive. For example, across all LU sites, similarity was affected by Fabaceae (Cordyla africana, Cynometra webberi, Dichrostachys cinerea, Erythrina abysinica, and Hymenea verrucosa). These few species were more frequent than other species across LU sites. Therefore, disturbances seem to limit the regenerability of some species in different areas (Eales et al. 2016).

The IVI was below that reported by Devi and Yadava (2006), perhaps due to differences in disturbance levels, geographic locations, and basal areas from one ecological system to another. However, some individual trees in CFS had high IVI just as in other tropical forests (Mligo 2015). The IVI in our study sites show that disturbances have substantial impacts on different species. That is why trees such as Tamarindus indica in CFS had an IVI up to $20 \%$, while in ADS the highest value was only $14 \%$ for Brachystegia boehmii, Combretum schumannii, and Mimusops zeyheri. In addition, the IVI in LGS reached $10 \%$ for Combretum schumannii and Tamarindus indica. The IVI in the disturbed sites was below CFS, possibly from poor seed dispersal, competition, and low soil nutrient availability (Hooper et al. 2005). The IVI indicated that the impacts of disturbances affect individual species to different degrees, which in turn affects coastal forest structural settings and possibly some functions and services, agreeing with Bargali et al. (2013). However, the impacts of disturbances in services were not assessed in this study, thus opening another area for further investigation.

\section{Conclusion}

Crop-agriculture and livestock-disturbed sites contributed to variability in numbers, basal area, volume, and species diversity and richness in the Uzigua Forest Reserve. Disturbed sites had differential successional regeneration impacts on tree variables and diversity. The differences in regeneration between and across land-uses show that anthropogenic disturbances in the coastal forests can have positive and negative impacts. High population density of seedlings and saplings in the disturbed sites shows that the exclusion of human activities (agriculture and livestock grazing) enhances regeneration in quantity, but to a lesser extent in diversity. Thus, exclusion is a good management option because it permits natural and quick coastal forest recovery. However, species diversity variances across landuses indicates that exclusion should be practiced even where the forest is already degraded. It is important that environmentalists, ecologists, foresters, livestock and agriculture practitioners be aware that the regeneration response is better in crop-agriculture sites than in grazed lands. Therefore, attention must be paid to the current overgrazing practices in the coastal forests; otherwise, the ongoing pace of livestock grazing will continue to negatively affect forest ecosystems. That said, species variations in crop-agriculture and livestock-disturbed sites compared with closed forests sites 3 years after the exclusion of human activities might provide only partial information. Therefore, further studies are required to map coastal forest regeneration and dynamics for sustainable forest management.

Acknowledgements Thanks to the Department of Ecology, Forestry and Life Sciences Colleges, Fujian Agriculture and Forestry University, Fuzhou, Fujian, China for supporting this work. Thanks to Christine Vogelsang, Job Wilson and Laura Willemsen for language help and proofreading the article. Finally, we thank all who in one way or another have contributed to make this article fruitful.

Author's contribution This study was carried out with the collaboration of all authors. EJL and CC designed the study, collected and analyzed the data, and wrote the first draft of the manuscript. CW managed the literature searches and coordinated all field logistics for data collection and analysis. All authors read and approved the final manuscript.

\section{Compliance with ethical standards}

Conflict of interest Authors have declared that no competing interests exist.

Open Access This article is distributed under the terms of the Creative Commons Attribution 4.0 International License (http://crea tivecommons.org/licenses/by/4.0/), which permits unrestricted use, distribution, and reproduction in any medium, provided you give appropriate credit to the original author(s) and the source, provide a 
link to the Creative Commons license, and indicate if changes were made.

\section{References}

Amato AWD, Fraver S, Palik BJ, Bradford JB, Patty L (2011) Singular and interactive effects of blowdown, salvage logging, and wildfire in Sub-boreal pine systems. For Ecol Manag 262(11):2070-2078

Amlin G, Suratman MN, Isa NM (2014) Soil chemical analysis of secondary forest 30 years after logging activities at Krau Wildlife Reserve, Pahang, Malaysia. APCBEE Procedia 9:75-81

Ares A, Terry T, Harrington C, Devine W, Peter D (2007) Biomass removal, soil compaction and vegetation control effects on fiveyear growth. For Sci 53(5):600-610

Axelsson C, Jones S, Haywood A, Suarez L, Wilkes P, Woodgate W, Soto-Berelov M, Mellora A (2012) Key attributes for monitoring and assessment of Australian forests: A land management perspective. In: CEUR workshop proceedings, vol 1328, pp 1-9

Bargali K, Bisht P, Khan A, Rawat YS (2013) Diversity and regeneration status of tree species at Nainital Catchment, Uttarakhand, India. Int J Biodivers Conserv 5(May):270-280

Bharathi S, Prasad AGD (2015) Regeneration status of tree composition in the sacred groves of Mercara, Central Western Ghats. Eur J Exp Biol 5(10):29-40

Bonari G, Acosta ATR, Angiolini C (2017) Mediterranean coastal pine forest stands: understorey distinctiveness or not? For Ecol Manag 391:19-28

Carnevale NJ, Montagnini F (2002) Facilitating regeneration of secondary forests with the use of mixed and pure plantations of indigenous tree species. For Ecol Manag 163(1-3):217-227

Cierjacks A, Rühr NK, Wesche K, Hensen I (2008) Effects of altitude and livestock on the regeneration of two tree line forming Polylepis species in Ecuador. Plant Ecol 194(2):207-221

Comita LS (2014) Drought as a driver of tropical tree species regeneration dynamics and distribution patterns. In: David AC, David FR, Burslem P, Simonson WD (eds) Forests and global change. Cambridge University Press, Cambridge, pp 1-48

Defries R, Rovero F, Wright P, Ahumada J, Andelman S, Brandon K, Dempewolf J, Hansen A, Hewson J, Liu J (2010) From plot to landscape scale: linking tropical biodiversity measurements across spatial scales. Front Ecol Environ 8(3):153-160

Devi SL, Yadava PS (2006) Floristic diversity assessment and vegetation analysis of tropical semievergreen forest of Manipur, North East India. Trop Ecol 47(1):89-98

Dharani N (2011) Field guide to common trees and shrubs of East Africa. Random House Struik, Cape Town, pp 1-320

Duah-gyamfi A, Kyereh B, Adam KA, Agyeman VK, Swaine MD (2014) Natural regeneration dynamics of tree seedlings on skid trails and tree gaps following selective logging in tropical moist semi-deciduous forest in Ghana. J For 4(1):49-57

Eales J, Haddaway NR, Bernes C, Cooke SJ, Jonsson BG, Kouki J, Petrokofsky G (2016) What is the effect of prescribed burning in temperate and boreal forest on biodiversity, beyond tree regeneration, Pyrophilous and Saproxylic species? Environ Evid 5(24): $1-8$

Eludoyin OS (2016) Understorey vegetation assessment in Gmelina arborea (roxb.) plantations of different ages in Omo Forest Reserve, Southwestern Nigeria. Nat Sci 14(10):92-101

Godoy FL, Tabor K, Burgess ND, Mbilinyi BP, Kashaigili JJ, Steininger MK (2011) Deforestation and CO2 emissions in coastal Tanzania from 1990 to 2007. Environ Conserv 39(1):62-71
Golluscio RA, Austin AT, García Martínez GC, Gonzalez-Polo M, Sala OE, Jackson RB (2009) Sheep grazing decreases organic carbon and nitrogen pools in the Patagonian steppe: combination of direct and indirect effects. Ecosystems 12(4):686-697

Guerrero PC, Bustamante RO (2007) Can native tree species regenerate in Pinus radiata plantations in Chile? Evidence from field and laboratory experiments. For Ecol Manag 253(1-3):97-102

Halter R (2016) The use versus availability of wood extraction at the Baga II Forest Reserve adjacent to Kizanda Village in the West Usambara Mountains: Dar es Salaam, Tanzania, Paper 2350, pp 1-25. http://www.digitalcollections.sit.edu/ispcollection.pdf. Accessed 10 May 2017

Hessenmöller D, Elsenhans AS, Schulze ED (2013) Sampling forest tree regeneration with a transect approach. Ann For Res 56(1):3-14

Hitimana J, Kiyiapi JL, Njunge JT (2004) Forest structure characteristics in disturbed and undisturbed sites of Mt. Elgon moist lower montane forest. Western Kenya. For Ecol Manag 194(1-3):269-291

Hooper E, Condit R, Legendre P (2002) Responses of 20 native tree species to reforestation strategies for abandoned farmland in Panama. Ecol Appl 12(6):1626-1641

Hooper E, Legendre P, Condit R (2005) Barriers to forest regeneration of deforested and abandoned land in Panama. J Appl Ecol 7:1165-1174

Huang W, Pohjonen V, Johansson S, Nashanda M (2003) Species diversity, forest structure and species composition in Tanzanian tropical forests. For Ecol Manag 173(14):11-24

Hunter MO, Keller M, Victoria D, Morton DC (2013) Tree height and tropical forest biomass estimation. Biogeosciences 10:8385-8399

Jayakumar S, Kim SS, Heo J (2011) Floristic inventory and diversity assessment-a critical review. In: Proceedings of the international academy of ecology and environmental sciences: Unit 3, 6/F., Kam Hon Industrial Building, 8 Wang Kwun Road, Kowloon Bay, Hong, (1), pp 151-168

Jones ER, Wishnie MH, Deago J, Sautu A, Cerezo A (2004) Facilitating natural regeneration in Saccharum spontaneum (L.) grasslands within the Panama Canal Watershed: effects of tree species and tree structure on vegetation recruitment patterns. For Ecol Manag 191(1-3):171-183

Joyi O, Utanga MM, Dindi OO, Ynekulu J, Ahman EB (2015) The effect of forest fragmentation on tree species abundance and diversity in the Eastern Arc Mountains of Tanzania. Appl Ecol Environ Res 13(2):307-324

Kalaba FK, Quinn CH, Dougill AJ, Vinya R (2013) Floristic composition, species diversity and carbon storage in charcoal and agriculture fallows and management implications in Miombo woodlands of Zambia. For Ecol Manag 304:99-109

Keenan RJ, Reams GA, Achard F, Freitas JV, Grainger A, Lindquist E (2015) Forest ecology and management dynamics of global forest area : results from the FAO Global Forest Resources Assessment. For Ecol Manag 352:9-20

Kimaro J, Lulandala L (2013) Forest cover and land use change in Ngumburuni. J Environ Ecol 4(2):113-125

Lovett C, Ruffo C, Gereau R, Taplin RJ (2006) Field guide to the moist forest trees of Tanzania. Society for Environmental Exploration, London, pp 1-303

Lu Y, Sailesh R, Rhett DH, Jianchu X, Xiaokun O, Xuelan M, Jun H (2017) Selection of native tree species for subtropical forest restoration in Southwest China. PLoS ONE 12(1):1-15

Majumdar K, Datta BK (2014) Vegetation types, dominant compostion, wood plant diversity and stand structure in Trishna Wildlife Sancuary of Nothereast India. J Environ Biol 36:409-418 
Merganic J, Merganicova K, Marusak R, Audolenska V (2012) Plant diversity of forests. In: Juan AB, Yueh-Hsin L (eds) Forest ecosystem-more than just tree. InTech, Rijeka, pp 1-480

Mligo C (2015) Conservation of plant biodiversity of Namatimbili forest in the Southern Coastal Forests of Tanzania. Int J Biodivers Conserv 7(3): 148-172

Mligo C, Lyaruu H, Ndangalasi H (2009) Vegetation community structure, composition and distribution pattern in the Zaraninge Forest. J East African Nat Hist 98(2):223-239

Navroodi IH (2015) Effects of livestock exclusion on forest tree regeneration (Case study : ramsar District in Iran). J For Sci 61(1):1-6

Philip MS (1983) Measuring trees and forests. University of Dar es Salaam Press, Dar es Salaam, pp 1-338

Potter C (2014) Global assessment of damage to coastal ecosystem vegetation from tropical storms. Remote Sens Lett 5(4):315-322

Schieltz JM, Daniel IR (2016) Evidence based review: positive versus negative effects of livestock grazing on wildlife. What do we really know? Environ Res Lett 11(11):1-18

Shankar U (2001) A case of high tree diversity in a Sal (Shorearobusta) dominated lowland forest of Eastern Himalaya: floristic composition, regeneration and conservation. Curr Sci 81(7):776-786

Shannon CE, Wiener W (1963) The mathematical theory of communication. University of Illinois Press, Urbana, pp 1-126

Silayo DA, Tarimo MCT, Kweka ARE, Muganda AM (2006) Impacts of human induced activities on species composition and diversity in Miombo woodlands of Bagamoyo district, Tanzania. J Korean Assoc Afr Stud 2:223-243

Simpson EH (1949) Measurement of diversity. Nature 163:688

Sundarapandian S, Swamy PS (2013) Short-term population dynamics of tree species in tropical forests at Kodayar in the Western Ghats of Tamil Nadu, India. In: Zhang W (ed) Proceedings of the international academy of ecology and environmental sciences, vol 3. International Academy of Ecology and Environmental Sciences, Madurai
Supriya D, Yadava PS (2006) Floristic diversity assessment and vegetation analysis of tropical semi-evergreen forest of Manipur, North East India. Trop Ecol 47(1):89-98

Tadesse SA, Kotler BP (2013) The impacts of humans and livestock encroachments on the habitats of mountain Nyala (Tragelaphusbuxtoni) in Munessa, Ethiopia. Int $\mathrm{J}$ Biodivers Conserv 5(9):572-583

Thompson I, Mackey B, McNulty S, Mosseler A (2009) Forest resilience, biodiversity, and climate change. A synthesis of the biodiversity/resilience/stability relationship in forest ecosystems: CBT technical series No. 43, Montreal, pp 1-69. http://doi.org/ 10.1007/978-3-642-10445-9_5.pdf. Accessed 12 June 2017

Tomppo E, Malimbwi R, Katila M, Mäkisara K, Henttonen HM, Chamuya N, Zahabu E, Otieno J (2014) A sampling design for a large area forest inventory. Can J For Res 44:931-948

URT (2015) National Forest Resources Monitoring and Assessment of Tanzania Mainland (NAFORMA): Main Results, Ministry of Natural Resources \& Tourism, Tanzania Forest Services Agency, The Government of Finland and Food and Agriculture Organization (FAO) of the United Nations, pp 1-37. http://www. fao.org/forestry/pdf. Accessed 15 May 2017

Ustuner M, Sanli FB, Dixon B (2015) Application of support vector machines for land use classification using high-resolution rapideye images: a sensitivity analysis. Eur J Remote Sens 48:403-422

Wekesa C, Leley N, Maranga E, Kirui B, Muturi G, Mbuvi M, Chikamai B (2015) Effects of forest disturbance on vegetation structure and above-ground carbon in three isolated forest patches of Taita Hills. Open J For 6:142-161

World Bank (2016) Managing Coasts with natural solutions: Guidelines for measuring and valuing the coastal protection services of mangroves and coral reefs. In: Beck MW, Lange G-M (eds) Wealth accounting and the valuation of ecosystem services partnership (WAVES), World Bank. World Bank Group, Washington, p 167. http://documents.worldbank.org/curated/en/ 995379786/pdf. Accessed 05 May 2017 